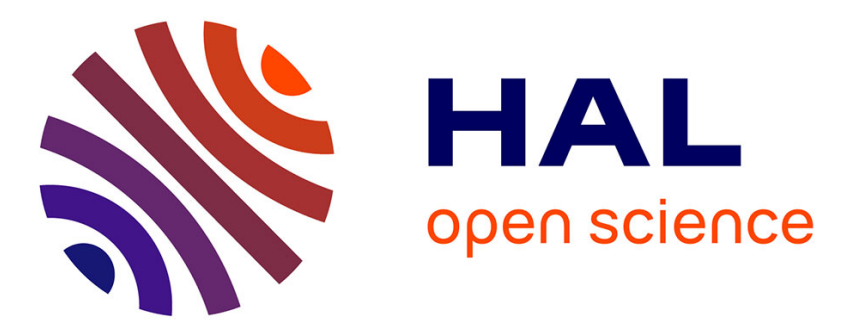

\title{
PDEs create local domains of cAMP signaling
}

Delphine Mika, Jérôme Leroy, Grégoire Vandecasteele, Rodolphe Fischmeister

\section{To cite this version:}

Delphine Mika, Jérôme Leroy, Grégoire Vandecasteele, Rodolphe Fischmeister. PDEs create local domains of cAMP signaling. Journal of Molecular and Cellular Cardiology, 2012, 52 (2), pp.323-329. 10.1016/j.yjmcc.2011.08.016 . hal-02940242

\section{HAL Id: hal-02940242 \\ https://hal.science/hal-02940242}

Submitted on 16 Sep 2020

HAL is a multi-disciplinary open access archive for the deposit and dissemination of scientific research documents, whether they are published or not. The documents may come from teaching and research institutions in France or abroad, or from public or private research centers.
L'archive ouverte pluridisciplinaire $\mathbf{H A L}$, est destinée au dépôt et à la diffusion de documents scientifiques de niveau recherche, publiés ou non, émanant des établissements d'enseignement et de recherche français ou étrangers, des laboratoires publics ou privés. 


\title{
PDEs create local domains of cAMP signalling
}

\author{
Delphine Mika $^{1,2}$, Jérôme Leroy ${ }^{1,2}$, Grégoire Vandecasteele ${ }^{1,2}$, \\ Rodolphe Fischmeister ${ }^{1,2 *}$
}

${ }^{1}$ INSERM UMR-S 769, Châtenay-Malabry, F-92296, France.

${ }^{2}$ Université Paris-Sud 11, Faculté de Pharmacie, Châtenay-Malabry, F-92296, France.

Key Words: Cyclic AMP, compartmentation, phosphodiesterases, heart

*Address correspondence to:

Rodolphe Fischmeister

INSERM UMR-S 769

Faculté de Pharmacie, Université Paris-Sud 11

5 Rue Jean-Baptiste Clément

F-92296 Châtenay-Malabry

France

Tel.: 33-1-46 835771

Fax: 33-1-46 835475

E-mail: rodolphe.fischmeister@inserm.fr 


\begin{abstract}
In the light of the knowledge accumulated over the years, it becomes clear that intracellular cAMP is not uniformly distributed within cardiomyocytes and that cAMP compartmentation is required for adequate processing and targeting of the information generated at the membrane. Localized cAMP signals may be generated by interplay between discrete production sites and restricted diffusion within the cytoplasm. In addition to specialized membrane structures that may limit cAMP spreading, degradation of the second messenger by cyclic nucleotide phosphodiesterases (PDEs) appears critical for the formation of dynamic microdomains that confer specificity of the response to various hormones. This review will cover the role of the different cAMP-PDE isoforms in this process.
\end{abstract}

\title{
1. Introduction
}

The cAMP pathway is one of the most common and versatile signal pathways in eukaryotic cells and is involved in regulation of cellular functions in almost all tissues in mammals [1]. In the heart, the cAMP pathway regulates cardiac contractility, relaxation, automaticity, metabolism and gene expression. It is a major pathway involved in the sympathetic regulation of heart function [2]. In this setting, noradrenaline released from intracardiac nerve terminals activates cardiac $\beta$-adrenergic receptors ( $\beta$-ARs), which trigger in sequence $\mathrm{G}_{\mathrm{s}}$ protein activation of adenylyl cyclase (AC), cAMP synthesis and protein kinase A (PKA) activation. PKA then phosphorylates several key proteins involved in excitation-contraction (EC) coupling, such as L-type $\mathrm{Ca}^{2+}$ channels (LTCC), phospholamban (PLB), ryanodine receptors (RyR), troponin I (TnI) and myosin binding protein-C (MyBP-C) [3]. Cyclic AMP has also PKA-independent targets in the heart, such as the small G protein exchange factor Epac (Exchange Protein directly Activated by $\underline{\mathrm{c} A M P}$ ) [4] involved in hypertrophic growth [5,6] and HCN cyclic nucleotide-gated ion channels underlying the pacemaker current, If [7].

There is a large body of data supporting the hypothesis that cAMP signaling in cardiac cells occurs within discrete subcellular compartments (reviewed in [8]). Early evidence for the compartmentation of cAMP signaling was provided by the observation that activation of $\beta$-ARs by catecholamines and of prostanoid EP receptors (EP-R) by prostaglandin $\mathrm{E}_{1}\left(\mathrm{PGE}_{1}\right)$ similarly increased cAMP but elicited different effects in isolated perfused hearts $[9,10]$. A first clue to this paradoxical observation was the identification of two PKA isozymes (PKAI and PKAII) in myocardium, differing by the nature of their 
regulatory subunits (called RI and RII) and by their distribution: whereas PKAI was mostly soluble, PKAII was associated to the particulate fraction $[9,11]_{.}$. Whereas $\beta$-AR stimulation activated cAMP-dependent protein kinase (PKA) in both soluble and particulate fractions and caused activation of glycogenolytic enzymes and phosphorylation of the myofilament protein troponin I (TnI), EP-R stimulation only increased PKA in the soluble fraction and failed to stimulate glycogen metabolism, contractile activity and TnI phosphorylation [12-15]. Similar results were reproduced in isolated myocytes, thus indicating that the differences observed had a subcellular basis and were not due to the different cell types present in the whole heart [12]. Subsequently, $\beta_{1}$-ARs and $\beta_{2}$-ARs were found to elicit qualitatively different responses in isolated cardiac myocytes. In contrast to $\beta_{1}-\mathrm{AR}$ stimulation, which leads to the phosphorylation of LTCC, RyR2, PLB, TnI and MyBP-C, in rat ventricular myocytes $\beta_{2}-\mathrm{AR}$ signalling appears restricted to the plasma membrane and LTCC regulation, thus inducing a modest inotropic effect without hastening relaxation [16-18]. A similarly localised $\beta_{2}-A R$ signaling occurs in dog ventricular myocytes, although in this case $\beta_{2}$-AR stimulation still accelerates relaxation $[17,19,20]$. However, others found that in rat ventricular myocytes, $\beta_{2}$ AR stimulation enhanced PKA-dependent PLB phosphorylation and accelerated relaxation, although it failed to phosphorylate TnI and phosphorylase $a$ [21]. Besides $\beta$-ARs and EP-R, a given cardiac myocyte expresses several other receptors coupled to stimulatory G proteins (GsPR), for instance glucagon receptors (Glu-R) and glucagon-like peptide-1 receptors (GLP1-R). Activation of these receptors also leads to cAMP elevation, however the contractile and metabolic effects of Glu-R are typically not sustained (tachyphylaxis) [22,23] whereas GLP1-R stimulation exerts a modest negative inotropic effect despite an increase in total cAMP which is comparable to that elicited by a $\beta$-AR stimulation [24]. Recently, electrophysiological and imaging approaches that resolve cAMP signals at the subcellular level in intact cardiomyocytes confirmed that $\beta_{1}-\mathrm{AR}, \beta_{2}-\mathrm{AR}, \mathrm{EP}-\mathrm{R}, \mathrm{Glu}-\mathrm{R}$ and GLP1-R generate distinct cAMP signals that differentially regulate PKA targets such as LTCC, PLB, and TnI [25-28]. Using ratiometric fluorescence resonance energy transfer (FRET) sensors for cAMP fused with the dimerization/docking domain of the RI $\alpha$ and the RII $\beta$ regulatory subunits of PKA, Di Benedetto et al. [27] showed that cAMP generated by isoprenaline (Iso) increases cAMP preferentially in the RII compartment, whereas GLP-1, glucagon and PGE 1 stimulation resulted in larger increases in CAMP in the RI compartment. This was associated with the phosphorylation of PLB, TnI and $\beta_{2}$-AR by Iso but not by PGE1. Altogether, these observations indicate that the cell is able to distinguish between different stimuli acting via the same second messenger, and raise the question of the mechanisms involved. 
A first element to answer this question is the uneven localization of the components of the cAMP signaling pathway within discrete compartments of the cell. In ventricular cells, invagination of the plasma membrane forms a transverse tubular network whose major function is the synchronization of $\mathrm{Ca}^{2+}$ release during excitation-contraction coupling (ECC) [29]. Together with proteins involved in $\mathrm{Ca}^{2+}$ movements across the plasma membrane, such as LTCC [30,31], the $\mathrm{Na}^{+} / \mathrm{Ca}^{2+}$ exchanger [32] and the plasma membrane $\mathrm{Ca}^{2+}$ ATPase $[33,34]$, several components of the cAMP pathway were found to be enriched in the Ttubules: $\mathrm{G}_{\mathrm{s}}$ proteins [35], AC5/6 [30,35], phosphodiesterase (PDE) type 3 and 4 [36,37], PKA regulatory subunits and anchoring proteins (AKAPs) [38]. So far, G $\mathrm{PCR}$ localization in cardiac myocytes has proved difficult due to low expression levels of these proteins and insufficient antibody specificity. Using an elegant combination of scanning ion conductance microscopy with cAMP imaging by FRET, Nikolaev et al. recently provided evidence that $\beta_{2}$-ARs are localized in T-tubules in healthy ventricular myocytes, in contrast to $\beta_{1}$-ARs which are more evenly distributed throughout the plasma membrane [39]. Other microdomains of high interest for cAMP signal transduction are caveolae, where a number of components of the cAMP pathway were shown to be localized [40]. The role of caveolae in signalling compartmentation being the focus of an accompanying review, it will not be developed here.

Within the above described microdomains, cAMP signalling components are organized into multiprotein complexes, an arrangement that increases both efficiency and specificity of the transduction cascade. AKAPs play an essential role in these arrangements. AKAPs form a large family of proteins comprising $>50$ members whose primary function is to anchor PKA in the vicinity of its substrates, thus ensuring the preferential phosphorylation of a limited number of targets [41]. Importantly, AKAPs not only bind PKA but act as scaffold proteins for other signalling components including phosphatases 1 and 2 [42,43], Epac [44], adenylyl cyclase (AC) type 5/6 [45] and PDE4D [44,46,47]. More details about AKAPs in cardiac signalling can be found in an accompanying review in this issue of $J M C C$.

How is the specificity of the response to the various hormones maintained when they share a small diffusible molecule such as cAMP? Localized cyclic nucleotide signals may be generated by the interplay between discrete production sites and restricted diffusion within the cytoplasm. Restricted diffusion of cAMP may be achieved by several means. A first possibility is that physical barriers are created by specialized membrane structures within the cytoplasm. This was initially proposed to explain the differences in cAMP concentration elicited by PGE1 at the plasma membrane and in the bulk cytosol of HEK293 cells, although 
an experimental proof that this actually occurs is still lacking [48]. However, another important mechanism that limits cAMP diffusion is cAMP buffering by PKA regulatory subunits $[39,49]$ and degradation of the second messenger by PDEs, which appears critical for the formation of dynamic microdomains that confer specificity of the response $[2,41]$.

\section{PDEs and cAMP compartmentation}

At least 11 PDE families including 20 genes and about 50 isoforms are identified on the basis of primary amino acid (AA) sequence as well as kinetic and regulatory properties [50]. All PDEs harbor a C-terminal catalytic domain of about 270 AA, of which $20-25 \%$ are identical in isozymes belonging to different subfamilies. On the other hand, the N-terminal regulatory domain of PDEs has a unique AA sequence in each PDE subfamily, and it contains dimerization domains, binding sites for specific regulators of isozyme activity as well as phosphorylation sites targeted by protein kinases, and membrane-associated domains anchoring PDE isozymes to discrete subcellular compartments [50,51]. Classically, 4 of these 11 PDE families are responsible for cAMP degradation in heart [52]: PDE1, PDE2, PDE3 and PDE4. While PDE1 and PDE2 can hydrolyse both cAMP and cGMP, PDE3 preferentially hydrolyses cAMP and PDE4 is specific for cAMP. PDE1 is activated by $\mathrm{Ca}^{2+} /$ calmodulin complex; PDE2 is stimulated by cGMP binding to amino terminal allosteric regulatory sites known as GAF domains; PDE3 has a similar $\mathrm{K}_{\mathrm{m}}$ for cAMP and cGMP but a higher $V_{\max }$ for the former, making it a cGMP-inhibited cAMP-PDE; and PDE4 is activated by PKA [51]. PDE1 is encoded by 3 genes (PDE1A-C), PDE2 by one gene (PDE2A), PDE3 by 2 genes (PDE3A and PDE3B) and PDE4 by 4 genes (PDE4A-D). Cardiac myocytes express 2 forms of PDE2A [53], 3 forms of PDE3A [54] and more than 5 forms of PDE4 encoded by $P D E 4 A, P D E 4 B$ and PDE4D [55-57]. A fifth PDE, PDE8A, specifically hydrolyzes cAMP and was shown recently to control ECC in mouse cardiac myocytes [58].

Many studies investigated PDE activities in heart homogenates or isolated cardiomyocytes. While the four PDE isoenzymes (PDE1, PDE2, PDE3 and PDE4) are present in mammalian cardiac tissue, their level of expression is highly dependent on the species investigated. In rats and mice, PDE4 represents the major cAMP-PDE, contributing for up to $60 \%$ of total cAMP-hydrolytic activity, whereas PDE3 accounts for 20 to $30 \%$ [5962], and PDE2 and PDE1 representing the remaining activity. The prevalence of PDE4 is further exaggerated because PKA phosphorylates and activates the long forms of these enzymes $[63,64]$. In rat cardiac myocytes, this provides an important negative feedback loop 
by which PKA limits excessive cAMP accumulation during $\beta$-AR stimulation $[46,61,65]$. In the heart of other rodents such as rabbits, guinea pigs or hamsters, PDE1 was found to be predominant followed by PDE2 and PDE3, with less activity represented by PDE4 [66-68]. In human heart, PDE4 activity represents only $10 \%$ of total PDE activity [62,62,66-68] while other PDE families represent the vast majority of the hydrolytic cAMP activity $[62,69]$ distributed between PDE1, PDE2 and PDE3 [62,69,70].

An early evidence of the contribution of PDEs to intracellular cyclic nucleotide compartmentation was obtained by comparing the effects of the non selective $\beta$-AR agonist Iso, or the nonselective PDE inhibitor, 3-isobutyl-1-methylxanthine (IBMX), or the PDE3 inhibitor, milrinone, in guinea pig perfused hearts. Whereas each of these treatments increased intracellular cAMP and produced positive inotropic and lusitropic effects, differences in the phosphorylation pattern of PLB, TnI and MyBP-C by PKA were observed [71]. These results were attributed to a functional cellular compartmentation of cAMP and PKA substrates due to a different expression of PDEs at the membrane and in the cytosol [72]. In canine ventricular myocytes, increase in particulate but not total cAMP correlated with increase in $\mathrm{Ca}^{2+}$ transient amplitude and decay kinetics [73]. In response to $\beta$-AR stimulation, about $45 \%$ of the total cAMP was found in the particulate fraction but this fraction declined to $<20 \%$ when IBMX was added to Iso, although cAMP production was up to 3-4 fold greater. These results show that cAMP-PDEs reside predominantly in the cytoplasm, where they prevent excessive cAMP accumulation upon $\beta$-AR activation. Thus PDEs appear important to maintain the specificity of the $\beta$-AR response by limiting the amount of cAMP diffusing from membrane to cytoplasm. Similar results were obtained when studying the impact of PDE inhibition on LTCC current ( $\left.\mathrm{I}_{\mathrm{Ca}, \mathrm{L}}\right)$ regulation by local application of Iso in frog ventricular myocytes [74]. In the absence of IBMX, application of Iso to half of the cell increased ICa,L half maximally, corresponding to activation of the channels located in the same part of the cell as the $\beta$-AR agonist. When IBMX was added with Iso on one half of the cell, the effect of Iso was greatly potentiated because in this condition, LTCCs in the remote part of the cells could be recruited. Thus, these results suggest that PDE activity is important for the definition of local cAMP pools involved in the $\beta$-AR stimulation of LTCCs. Subsequent studies using ratiometric FRET biosensors to directly monitor cAMP have shown that the second messenger increases preferentially in discrete microdomains corresponding to the dyad region under $\beta$-AR stimulation, and that cAMP diffusion is limited by PDE activity [75,76]. Subsequent studies using recombinant cyclic nucleotide gated channels to measure cAMP generated at the plasma membrane identified specific functional coupling of 
individual PDE families to $\beta \square-A R, \beta_{2}-A R, P G E_{1}-R$ and Glu-R as a major mechanism enabling cardiac cells to generate heterogeneous cAMP signals in response to different hormones [61].

The use of selective inhibitors for each PDE family has allowed evaluating the contribution of these enzymes in the compartmentation of cAMP signaling pathways in cardiac myocytes. However, because of the lack of a commercially available selective PDE1 inhibitor, the role of this PDE family in cardiac function has been limited to few studies [70,77].

\section{Role of PDE isoforms in cAMP compartmentation}

\subsection{PDE2 and cAMP compartmentation}

In rat and frog cardiomyocytes, PDE2 is found preferentially in microsomal fractions $[78,79]$ in association with functional membrane structures: plasma membrane, sarcoplasmic reticulum (SR), Golgi, nuclear envelope [80]. Although PDE2 activity is relatively small compared to other cardiac PDEs, PDE2 tightly controls the activity of LTCCs in various species including humans [81-86]. The involvement of PDE2 in the cyclic nucleotide compartmentation has been also examined on frog cardiomyocytes [84] where it is the most abundant PDE isozyme [78]. The authors have shown that a stimulation of the soluble guanylyl cyclase leads to a dramatic local decrease in cAMP in the vicinity of LTCCs due to the activation of PDE2, and only a slight decrease in cAMP in the rest of the cell. This phenomenon is explained by the existence of a microdomain between the $\beta$-AR, the LTCC and PDE2 [84]. More recently, a study realized on neonatal rat cardiomyocytes using the FRET-based imaging technique has demonstrated that PDE2 restricts cAMP signals, and hence inotropism, generated after a $\beta$-AR stimulation by Iso. This effect might involve the $\beta_{3}-$ AR and the NO/cGMP pathway [79]. PDE2 is not only involved in the modulation of subsarcolemmal cAMP concentration, but also controls the concentration of cGMP in that compartment $[87,88]$. A recent study showed that localized cAMP responses are profoundly modulated by cGMP, under $\beta$-AR stimulation [89]. The authors have identified PDE2 and PDE3 as effectors of such modulation and have demonstrated that cGMP alters the local activation of PKA isoforms (PKA-RI and PKA-RII) localized to different subcellular compartments, modifying the phosphorylation of downstream targets and cell contraction. In their model, PDE2 activity is preferentially coupled to PKA-RII compartment and PDE3 to PKA-RI compartment in the presence of catecholamines, and cGMP-mediated activation of 
PDE2 and inhibition of PDE3 are responsible for the opposing effects of cGMP on local cAMP signals [89].

\subsection{PDE3 and cAMP compartmentation}

That PDE3 plays a role in cAMP compartmentation is anticipated because of its intracellular distribution. Furthermore, because PDE3 is inhibited by cGMP, localized production of cGMP participates in shaping cAMP signals produced during $\beta$-AR stimulation, leading to restricted increases in cAMP concentration [89]. PDE3 is present in membrane and cytosolic fractions of cardiomyocytes with a species- and tissue-specificity $[80,90]$. For instance, in dog heart, where PDE3 inhibitors exert a potent positive inotropic effect, PDE3 activity revealed in membrane fraction is associated with the SR membrane [36,72,91]. Thus, PDE3 inhibition leads to a local increase of cAMP levels and PKA activation, responsible for the phosphorylation of PLB [92]. In contrast, in guinea pig and rat, PDE3 is mainly found in the soluble fraction and PDE3 inhibitors have more modest effects [72]. Two genes encode two PDE3 subfamilies, namely PDE3A and PDE3B. PDE3A is expressed in rat, guinea-pig, dog and human myocardium [54,57,93,94] and both PDE3A and PDE3B were found to coexist in mouse ventricular myocytes [95] (but see [92]). In human myocardium, three isoforms of PDE3A appear to be generated by alternative splicing of the PDE3A gene and post-transcriptional processing, giving rise to isoforms with different $\mathrm{N}$ terminus length with singular association domains as well as phosphorylation sites by PKB and PKA [54,69], the latter representing an important feedback to control cAMP levels in cardiomyocytes [65]. This allows preferential targeting of PDE3A in different compartments of the cell, and hence cAMP compartmentation. In mouse heart, PDE3B is found in a complex with PI3K $\gamma$ at the level of sarcolemmal membrane [95]. In this study, the authors have demonstrated that PI3K $\gamma$ activates PDE3B in a kinase-independent manner, by acting as an anchoring protein which recruits PDE3B into a membrane compartment where cAMP homeostasis shapes the chronic sympathetic drive [95]. More recently, these authors have discovered that PI3K $\gamma$ anchors PKA through a site in its $\mathrm{N}$-terminal region, and that anchored PKA activates PDE3B to enhance cAMP degradation [96]. This mechanism may represent an important negative feedback regulation of $\beta$-AR stimulation of LTCCs by PDE3 activity [97]. However, this finding was recently challenged by a study showing that PI3K $\gamma$ is only necessary for the PDE4 activity regulating the SERCA2a-PLB function and SR $\mathrm{Ca}^{2+}$ content, 
but not for the control of the cAMP/PKA dependent phosphorylation of LTCC and RyR2 [92].

\subsection{PDE4 and cAMP compartmentation}

Unlike PDE2 and PDE3, PDE4 is specific for cAMP and is not regulated by cGMP. In adult ventricular myocytes from rat and mice, PDE4 has no effect on basal cAMP levels but becomes crucial to hydrolyze cAMP generated during $\beta$-AR stimulation $[25,37,60,61,65,98]$ and for the control of PKA phosphorylation of key proteins involved in ECC such as LTTC [61,99], RyR2 [100] and PLB [92]. As a consequence, PDE4 inhibition strongly potentiates the inotropic effects of $\beta$-AR stimulation in these species [101-104]. However, although less studied, the role of PDE4 appears more modest in larger mammals and in humans. In human atrium, $\beta$-AR inotropic responses are predominantly regulated by PDE3 [105,106]. In vivo, a positive inotropic effect of PDE4 inhibitors was reported in dog, which was abolished by $\beta$-blockers, suggesting a presynaptic action on norepinephrine release [72]. [56]The PDE4 family is encoded by four different genes $(A, B, C$ and $D)$ but only $P D E 4 A, P D E 4 B$ and $P D E 4 D$ are expressed in cardiac tissue [55]. These three genes give rise to multiple isoforms generated through alternative splicing and by the use of different promoters [107]. A constantly growing body of literature concerns the PDE4D subfamily, with PDE4D3, PDE4D5, PDE4D8 and PDE4D9 being detected as active proteins in rat heart [56]. Less is known concerning a possible role for PDE4A and PDE4B isoforms to regulate cAMP levels and cardiac function, yet their activity has been detected in rodents and to a lesser extent in human myocardium [62]. However, PDE4B was shown to regulate cAMP levels near the plasma membrane in HEK293 cells [108] and to control $\beta$-AR signal termination in neonatal cardiomyocytes [37]. In a recent study, we have shown that both PDE4B and PDE4D can associate with the principal subunit of LTCC, but only PDE4B regulates $\mathrm{ICa}, \mathrm{L}_{\mathrm{L}}$ during $\beta$-AR stimulation in mouse ventricular myocytes. In ventricular myocytes from mice lacking PDE4B $\left(\mathrm{PDE}^{-/-}\right.$) challenged with Iso, enhanced ICa,L leads to augmented $\mathrm{Ca}^{2+}$ transients and shortening, but also to an increase in spontaneous $\mathrm{Ca}^{2+}$ release events. Upregulation of $\mathrm{I}_{\mathrm{Ca}, \mathrm{L}}$ and abnormal $\mathrm{Ca}^{2+}$ handling may explain the increased susceptibility of $\mathrm{PDE}^{-1 /} \mathrm{B}^{-/}$mice to ventricular arrhythmias under $\beta$-AR stimulation. These results emphasise the importance of strategically located phosphodiesterase isoforms for adequate control of cardiac ECC and arrhythmias [109].

Subcellular localization of PDE4 isoforms is mediated by their unique $\mathrm{N}$-terminal region which represents the postcode for their cellular distribution [110]. For instance, 
PDE4A1 contains a lipid-binding domain, TAPAS, with a specificity for phosphatidic acid that serves to target this enzyme to specific cellular membranes [111]. In the heart, PDE4D3 is localised in the sarcomeric region of the myocytes via an anchoring to myomegalin [112] and in the perinuclear region by an association with the muscle AKAP (mAKAP/AKAP6) $[44,46]$. This isoform is also found at the level of the dyads, associated with RyR2 [100], and in the sarcolemmal region associated with the KCNQ1/KCNE1 potassium channel responsible for $\mathrm{I}_{\mathrm{Ks}}$ [47]. It has been suggested that the cAMP compartment localized near the nucleus could control the import of the catalytic subunit of PKA into the nucleus and hence gene regulation [46,113]. The mAKAP not only binds PDE4D3 and PKA, but also Epac1 and the Erk5 kinase [44]. The 3 enzymes, PKA, PDE4D3 and Epac1 respond to cAMP in different concentration ranges: PKA responds to nanomolar concentrations while PDE4D3 and Epac1 are activated at micromolar cAMP concentrations and their inactivation would precede PKA holoenzyme reformation [44]. Furthermore, PDE4D3 phosphorylation by PKA on serine 54 leads to an increased activity [56,114] and phosphorylation on serine 13 increases its affinity for mAKAP [115]. In contrast, phosphorylation by Erk2 and 5 on serine 579 suppresses the activity of this enzyme [44,116]. When Epac1 is activated by cAMP, it recruits Rap1 which allows the suppression of Erk5 activation and relieves the inhibition of PDE4D3. This complex allows a spatial control of PKA activity by its anchoring to mAKAP, and a temporal regulation of cAMP signals by the presence of PDE in the immediate vicinity [1,46]. Interestingly, the expression and activity of PDE4D3 in the RyR2 complex is decreased in human heart failure [100]. These results highlight the importance of cAMP microdomains and suggest that a deregulation of a specific compartment may lead to pathological situations.

More recently, it has been demonstrated that PDE4D3, PKA and phosphatase 1 (PP1) are recruited at the KCNQ1/KCNE1 potassium channel via Yotiao/AKAP9 and contribute to the cAMP-dependent regulation of the potassium current IKs [47]. PDE4D5 and the scaffold $\beta$-arrestin protein are part of a complex organised around $\beta_{2}$-AR [117]. $\beta$-arrestins initiate desensitization of the receptors by their translocation from the cytosol to the plasma membrane. $\beta$-arrestins are able to form stable complexes with all PDE4 subfamilies, but PDE4D5 has a unique N-terminal region which confers a preferential interaction with $\beta$ arrestins. $\beta_{2}$-AR activation leads to cAMP production and AKAP79 (AKAP5)-anchored PKA activation [118]. PKA in turn phosphorylates the $\beta_{2}-\mathrm{AR}$, which triggers a shift in its coupling from $G_{s}$ to $G_{i}$, hence activating Erk kinase through a Src-regulated pathway [119]. The recruitment of $\beta$-arrestin-PDE4D5 complex stops the $\beta_{2}$-AR phosphorylation by PKA and 
prevents the shift to $\mathrm{G}_{\mathrm{i}}$-signaling cascade; conversely, disruption of this complex enhances PKA phosphorylation of the $\beta_{2}$-AR, leading to a dramatic change in its function $[119,120]$.

PDE4D5, PDE4D8 and PDE4D9 have been shown to interact directly or indirectly via $\beta$-arrestin with $\beta$-AR receptors in neonatal rat cardiomyocytes $[119,121,122]$. Whereas PDE4D5 is recruited to $\beta_{2}$-AR upon agonist stimulation, PDE4D8 is constitutively associated with the $\beta_{1}$-AR and dissociation occurs upon receptor activation [121]. More recently, $\beta_{2}$-AR was shown to interact also with PDE4D8 and with PDE4D9 [122]. $\beta_{2}$-AR stimulation induces the dissociation of PDE4D9 from the receptor and the recruitment of PDE4D8. These complex modes of interaction of $\beta$-AR subtypes with PDEs may shape divergent cAMP signals leading to specific physiological responses [122].

\section{4. cAMP-PDEs and Heart Failure}

A number of studies demonstrated a reduction in cAMP PDE expression and/or activity in various models of cardiac hypertrophy and/or HF: cardiomyopathic hamsters [68], failing dog hearts [123,124], mouse [125] and rat heart [57] subjected to transverse aortic constriction, including human HF [126]. On the contrary, PDEs that hydrolyze cGMP, such as PDE1A, PDE2 and PDE5, seem upregulated in hypertrophy [77,127,128]. Because PDEs are crucial orchestrator of cAMP signaling in cardiomyocytes [2], decreased cAMP PDE activities may lead to decompartmentation and loss of specificity of cAMP. PDE3 inhibition, initially described as a therapeutically relevant strategy to treat HF, has been associated with increased mortality in failing patients (see e.g. [129]). Such deleterious effects could be explained by the induction of the proapoptotic factor ICER (Inducible Cyclic AMP Early Repressor) occurring in a CREB dependent manner when PDE3 is inhibited [125,129]. The loss of a specific isoform, PDE3B at the plasma membrane, produces also dramatic cardiac damages in a chronic pressure overload animal model [95]. The decrease in PDE4 isoforms could promote electrophysiological remodelling by increasing the LTCC activity during hypertrophy, as reported in human failing ventricular myocytes [130] or prolongation of the action potential duration by increasing KCNQI/KCNE1 potassium channel phosphorylation by PKA [47,131]. Furthermore, in mice deficient for the PDE4D gene, RyR2 hyperphosphorylation by PKA and abnormal $\mathrm{Ca}^{2+}$ release result in increased sensitivity to exercise-induced arrhythmias and the development of a late onset dilated cardiomyopathy [100]. In addition, as shown above, PDE4D3 participates in a complex involving ERK5 and Epac1, two proteins involved in cardiomyocyte growth $[5,44]$. 


\section{Future directions}

In the light of the knowledge accumulated over the years, it becomes clear that cAMP is not uniformly distributed within cardiomyocytes and that PDEs play a crucial role in its confinement. A tenet in this field of research is that cAMP compartmentation is required for adequate processing and targeting of the information generated at the membrane. The compartmentation hypothesis relies on two central postulates [8]. The first is that not all PKA molecules phosphorylate all possible substrates in the cell. This condition is verified by the existence of AKAPs which specifically target PKA to its effectors [132]. The second postulate is that cAMP generated by a given AC does not activate all cellular PKAs. This condition may be verified by specific locations of cAMP-PDEs near ACs and cAMP effectors. Unveiling the details of this subcellular organization will require molecular, cellular and animal models to explore, in particular i) the cAMP signalosomes generated by AC5 and AC6, the two major adenylyl cyclases expressed in adult ventricular myocytes [133] whose specific function is yet unknown, ii) the role of PDE isoforms in shaping the cAMP compartments that specifically control the function of major effectors in cardiac ECC, iii) the role of cellular architecture. The compartmentation hypothesis needs also to be explored in other cardiac cell types, such as vascular cells where cAMP controls vasodilatation, cell growth and proliferation [134].

Another direction concerns cardiac pathophysiology and the difference between acute and chronic effects of cAMP. Although the cAMP pathway is beneficial on heart function under acute conditions, and is essential for the chronotropic, inotropic and lusitropic effects during the 'fight-or-flight' response, chronic activation of the cAMP pathway generally (but not always) induces hypertrophic growth and ventricular dysfunction [135], which ultimately leads to the development of chamber dilatation and HF [136]. Despite the description of a number of alterations in the cAMP pathway during hypertrophy and HF, the exact mechanisms accounting for the cardiotoxicity of this pathway are not fully understood. As discussed above, several cAMP PDEs are down regulated in an animal model of cardiac hypertrophy [57]. Does this lead to a disorganization of the cAMP compartmentation? To a loss of hormonal specificity? To cardiotoxic effects of cAMP? Does this contribute to the development of HF?

Finally, can a new therapeutic strategy emerge from the concept of cAMP compartmentation? A number of studies have demonstrated that PDEs are integral 
components of macromolecular complexes formed around specific target proteins, such as LTCCs $[2,25,74]$ or RyR2 [100]. Activation of these PDEs may therefore reduce chronic PKA phosphorylation of these proteins, reduce intracellular $\mathrm{Ca}^{2+}$ concentration, and prevent arrhythmias and sudden cardiac death. On the contrary, inhibition of PDE3A-136 associated with PLB in the SR membrane might allow preserving intracellular calcium fluxes and contractility in patients treated by $\beta$-blockers, without any concomitant arrhythmogenic effects [54,137]. To test these hypotheses, animal models with cardiac overexpression or silencing of specific PDE isoforms need to be generated and their cardiac function explored, under normal and stressed conditions. Such experiments will allow to test whether restoring a proper cAMP signaling might stop or reverse the development of HF.

\section{Acknowledgements}

Our own work reviewed here was supported by the Fondation Leducq for the Transatlantic Network of Excellence cycAMP grant 06CVD02 (to RF), the European Union contract LSHM-CT-2005-018833/EUGeneHeart (to RF), the Fondation de France (to GV), and ANR grant 2010 BLAN 1139-01 (to GV).

\section{References}

[1] Tasken K, Aandahl EM. Localized effects of cAMP mediated by distinct routes of protein kinase A. Physiol Rev 2004;84:137-167.

[2] Fischmeister R, Castro LRV, Abi-Gerges A, Rochais F, Jurevičius J, Leroy J, Vandecasteele G. Compartmentation of cyclic nucleotide signaling in the heart: The role of cyclic nucleotide phosphodiesterases. Circ Res 2006;99:816-828.

[3] Bers DM. Cardiac excitation-contraction coupling. Nature 2002;415:198-205.

[4] de Rooij J, Zwartkruis FJ, Verheijen MH, Cool RH, Nijman SM, Wittinghofer A, Bos $\mathrm{JL}$. Epac is a Rap1 guanine-nucleotide-exchange factor directly activated by cyclic AMP. Nature 1998;396:474-477.

[5] Morel E, Marcantoni A, Gastineau M, Birkedal R, Rochais F, Garnier A, Lompré AM, Vandecasteele G, Lezoualc'h F. The cAMP-binding protein Epac induces cardiomyocyte hypertrophy. Circ Res 2005;97:1296-1304.

[6] Métrich M, Lucas A, Gastineau M, Samuel J-L, Heymes C, Morel E, Lezoualc'h F. Exchange protein activated by cAMP (Epac) mediates $\beta$-adrenergic receptor-induced cardiomyocyte hypertrophy. Circ Res 2008;102:959-65.

[7] Barbuti A, DiFrancesco D. Control of cardiac rate by "funny" channels in health and 
disease. Ann N Y Acad Sci 2008;1123:213-23.

[8] Steinberg SF, Brunton LL. Compartmentation of G protein-coupled signaling pathways in cardiac myocytes. Ann Rev Pharmacol Toxicol 2001;41:751-773.

[9] Corbin JD, Keely SL. Characterization and regulation of heart adenosine 3':5'monophosphate-dependent protein kinase isozymes. J Biol Chem 1977;252:910-918 .

[10] Keely SL. Prostaglandin E1 activation of heart cAMP-dependent protein kinase: apparent dissociation of protein kinase activation from increases in phosphorylase activity and contractile force. Mol Pharmacol 1979;15:235-245.

[11] Corbin JD, Sugden PH, Lincoln TM, Keely SL. Compartmentalization of adenosine 3':5'-monophosphate and adenosine 3':5'-monophosphate-dependent protein kinase in heart tissue. J Biol Chem 1977;252:3854-3861.

[12] Buxton ILO, Brunton LL. Compartments of cyclic AMP and protein kinase in mammalian cardiomyocytes. J Biol Chem 1983;258:10233-10239.

[13] Hayes JS, Brunton LL, Mayer SE. Selective activation of particulate cAMPdependent protein kinase by isoproterenol and prostaglandin E1. J Biol Chem 1980;255:5113-5119.

[14] Brunton LL, Hayes JS, Mayer SE . Hormonally specific phosphorylation of cardiac troponin I and activation of glycogen phosphorylase. Nature 1979;280:78-80.

[15] Hayes JS, Brunton LL, Brown JH, Reese JB, Mayer SE. Hormonally specific expression of cardiac protein kinase activity. Proc Natl Acad Sci USA 1979;76:15701574.

[16] Xiao RP, Lakatta EG. $\beta_{1}$-Adrenoceptor stimulation and $\beta_{2}$-adrenoceptor stimulation differ in their effects on contraction, cytosolic $\mathrm{Ca}^{2+}$, and $\mathrm{Ca}^{2+}$ current in single rat ventricular cells. Circ Res 1993;73: 286-300.

[17] Xiao RP, Hohl C, Altschuld R, Jones L, Livingston B, Ziman B, Tantini B, Lakatta EG. $\beta_{2}$-adrenergic receptor-stimulated increase in cAMP in rat heart cells is not coupled to changes in $\mathrm{Ca}^{2+}$ dynamics, contractility, or phospholamban phosphorylation. J Biol Chem 1994;269:19151-19156.

[18] Calaghan S, Kozera L, White E. Compartmentalisation of cAMP-dependent signalling by caveolae in the adult cardiac myocyte. J Mol Cell Cardiol 2008;45:88-92.

[19] Altschuld RA, Starling RC, Hamlin RL, Billman GE, Hensley J, Castillo L, Fertel RH, Hohl CM, Robitaille PML, Jones LR, Xiao RP, Lakatta EG. Response of failing canine and human heart cells to beta(2)-adrenergic stimulation. Circulation 1995;92:1612-1618.

[20] Kuschel M, Zhou YY, Spurgeon HA, Bartel S, Karczewski P, Zhang SJ, Krause EG, Lakatta EG, Xiao RP. ß2-adrenergic cAMP signaling is uncoupled from phosphorylation of cytoplasmic proteins in canine heart. Circulation 1999;99:24582465. 
[21] Bartel S, Krause EG, Wallukat G, Karczewski P. New insights into $\beta_{2}$-adrenoceptor signaling in the adult rat heart. Cardiovasc Res 2003;57:694-703.

[22] Farah AE. Glucagon and the heart. Exp Pharmacol 1983;53:553-609.

[23] Juan-Fita MJ , Vargas ML, Kaumann AJ, Hernandez Cascales J. Rolipram reduces the inotropic tachyphylaxis of glucagon in rat ventricular myocardium. Naunyn Schmiedebergs Arch Pharmacol 2004;370:324-329.

[24] Vila Petroff MG, Egan JM, Wang X, Sollott SJ. Glucagon-like peptide-1 increases cAMP but fails to augment contraction in adult rat cardiac myocytes. Circ Res 2001;89:445-452.

[25] Rochais F, Abi-Gerges A, Horner K, Lefebvre F, Cooper DMF, Conti M, Fischmeister R, Vandecasteele G. A specific pattern of phosphodiesterases controls the cAMP signals generated by different $\mathrm{G}_{\mathrm{s}}$-coupled receptors in adult rat ventricular myocytes. Circ Res 2006;98:1081-1088.

[26] Warrier S, Ramamurthy G, Eckert RL, Nikolaev VO, Lohse MJ, Harvey RD. cAMP microdomains and L-type $\mathrm{Ca}^{2+}$ channel regulation in guinea-pig ventricular myocytes. J Physiol 2007;580:765-776.

[27] Di Benedetto G, Zoccarato A, Lissandron V, Terrin A, Li X, Houslay MD, Baillie GS, Zaccolo M. Protein kinase A type I and type II define distinct intracellular signaling compartments. Circ Res 2008;103:836-44.

[28] Agarwal SR, MacDougall DA, Tyser R, Pugh SD, Calaghan SC, Harvey RD. Effects of cholesterol depletion on compartmentalized cAMP responses in adult cardiac myocytes. J Mol Cell Cardiol 2011;50:500-9.

[29] Brette F, Orchard C. T-tubule function in mammalian cardiac myocytes. Circ Res 2003;92:1182-92.

[30] Gao TY, Puri TS, Gerhardstein BL, Chien AJ, Green RD, Hosey MM. Identification and subcellular localization of the subunits of L-type calcium channels and adenylyl cyclase in cardiac myocytes. J Biol Chem 1997;272:19401-19407.

[31] Hulme JT, Lin TW, Westenbroek RE, Scheuer T, Catterall WA. B-adrenergic regulation requires direct anchoring of PKA to cardiac $\mathrm{Ca}_{\mathrm{v}} 1.2$ channels via a leucine zipper interaction with A kinase-anchoring protein 15. Proc Natl Acad Sci USA 2003;100:13093-8.

[32] Yang Z, Pascarel C, Steele DS, Kornukai K, Brette F, Orchard CH. $\mathrm{Na}^{+}-\mathrm{Ca}^{2+}$ exchange activity is localized in the T-tubules of rat ventricular myocytes. Circ Res 2002;91:315-322.

[33] Despa S, Brette F, Orchard CH, Bers DM. Na/Ca exchange and Na/K-ATPase function are equally concentrated in transverse tubules of rat ventricular myocytes. Biophys J 2003;85:3388-3396.

[34] Chase A, Orchard CH. Ca efflux via the sarcolemmal Ca ATPase occurs only in the ttubules of rat ventricular myocytes. J Mol Cell Cardiol 2011;50:187-93. 
[35] Laflamme MA, Becker PL. Gs and adenylyl cyclase in transverse tubules of heart: implications for cAMP-dependent signaling. Am J Physiol Heart Circ Physiol 1999;277:H1841-H1848.

[36] Lugnier C, Muller B, Lebec A, Beaudry C, Rousseau E. Characterization of indolidan-sensitive and rolipram-sensitive cyclic nucleotide phosphodiesterases in canine and human cardiac microsomal fractions. J Pharmacol Exp Ther 1993;265:1142-1151.

[37] Mongillo M, McSorley T, Evellin S, Sood A, Lissandron V, Terrin A, Huston E, Hannawacker A, Lohse MJ, Pozzan T, Houslay MD, Zaccolo M. Fluorescence resonance energy transfer-based analysis of cAMP dynamics in live neonatal rat cardiac myocytes reveals distinct functions of compartmentalized phosphodiesterases. Circ Res 2004;95: 65-75.

[38] Yang JC, Drazba JA, Ferguson DG, Bond M. A-kinase anchoring protein 100 (AKAP100) is localized in multiple subcellular compartments in the adult rat heart. $\mathrm{J}$ Cell Biol 1998;142:511-522.

[39] Nikolaev VO, Moshkov A, Lyon AR, Miragoli M, Novak P, Paur H, Lohse MJ, Korchev YE, Harding SE, Gorelik J. $\beta_{2}$-Adrenergic receptor redistribution in heart failure changes cAMP compartmentation. Science 2010;327:1653-7.

[40] Ostrom RS, Gregorian C, Drenan RM, Xiang Y, Regan JW, Insel PA. Receptor number and caveolar co-localization determine receptor coupling efficiency to adenylyl cyclase. J Biol Chem 2001;276:42063-42069.

[41] Scott JD, Santana LF. A-kinase anchoring proteins: getting to the heart of the matter. Circulation 2010;121:1264-71.

[42] Marx SO, Reiken S, Hisamatsu Y, Jayaraman T, Burkhoff D, Rosemblit N, Marks AR. PKA phosphorylation dissociates FKBP12.6 from the calcium release channel (Ryanodine receptor): Defective regulation in failing hearts. Cell 2000;101:365-376.

[43] Marx SO, Kurokawa J, Reiken S, Motoike H, D'Armiento J, Marks AR, Kass RS. Requirement of a macromolecular signaling complex for $\beta$ adrenergic receptor modulation of the KCNQ1-KCNE1 potassium channel. Science 2002;295:496-499.

[44] Dodge-Kafka KL, Soughayer J, Pare GC, Carlisle Michel JJ, Langeberg LK, Kapiloff MS, Scott JD. The protein kinase A anchoring protein mAKAP co-ordinates two integrated cAMP effector pathways. Nature 2005;437:574-578 .

[45] Bauman AL, Soughayer J, Nguyen BT, Willoughby D, Carnegie GK, Wong W, Hoshi N, Langeberg LK, Cooper DM, Dessauer CW, Scott JD. Dynamic regulation of cAMP synthesis through anchored PKA-adenylyl cyclase V/VI complexes. Mol Cell 2006;23:925-931.

[46] Dodge KL, Khouangsathiene S, Kapiloff MS, Mouton R, Hill EV, Houslay MD, Langeberg LK, Scott JD. mAKAP assembles a protein kinase A/PDE4 phosphodiesterase cAMP signaling module. EMBO J 2001;20:1921-1930.

[47] Terrenoire C , Houslay MD, Baillie GS, Kass RS. The cardiac IKs potassium channel 
macromolecular complex includes the phosphodiesterase PDE4D3. J Biol Chem 2009;284:9140-6.

[48] Rich TC, Fagan KA, Nakata H, Schaack J, Cooper DMF, Karpen JW. Cyclic nucleotide-gated channels colocalize with adenylyl cyclase in regions of restricted cAMP diffusion. J Gen Physiol 2000;116:147-161.

[49] Saucerman JJ , Zhang J, Martin JC, Peng LX, Stenbit AE, Tsien RY, McCulloch AD. Systems analysis of PKA-mediated phosphorylation gradients in live cardiac myocytes. Proc Natl Acad Sci USA 2006;103:12923-12928.

[50] Beavo JA, Francis SH, Houslay MD. Cyclic nucleotide phosphodiesterases in health and disease. CRC Press, Taylor \& Francis Group, Boca Raton, Florida, USA 2007;pp. 1-713.

[51] Conti M, Beavo JA. Biochemistry and physiology of cyclic nucleotide phosphodiesterases: Essential components in cyclic nucleotide signaling. Ann Rev Biochem 2007;76:481-511.

[52] Osadchii OE. Myocardial phosphodiesterases and regulation of cardiac contractility in health and cardiac disease. Cardiovasc Drugs Ther 2007;21:171-94.

[53] Sonnenburg WK, Mullaney PJ, Beavo JA. Molecular Cloning of a Cyclic GMPStimulated Cyclic Nucleotide Phosphodiesterase cDNA - Identification and Distribution of Isozyme Variants. J Biol Chem 1991;266:17655-17661.

[54] Wechsler J, Choi YH, Krall J, Ahmad F, Manganiello VC, Movsesian MA. Isoforms of cyclic nucleotide phosphodiesterase PDE3A in cardiac myocytes. J Biol Chem 2002;277:38072-38078.

[55] Kostic MM, Erdogan S, Rena G, Borchert G, Hoch B, Bartel S, Scotland G, Huston E, Houslay MD, Krause EG. Altered expression of PDE1 and PDE4 cyclic nucleotide phosphodiesterase isoforms in 7-oxo-prostacyclin-preconditioned rat heart. J Mol Cell Cardiol 1997;29:3135-3146.

[56] Richter W, Jin SL, Conti M. Splice variants of the cyclic nucleotide phosphodiesterase PDE4D are differentially expressed and regulated in rat tissue. Biochem J 2005;388:803-811.

[57] Abi-Gerges A, Richter W, Lefebvre F, Matéo P, Varin A, Heymes C, Samuel J-L, Lugnier C, Conti M, Fischmeister R, Vandecasteele G. Decreased expression and activity of cAMP phosphodiesterases in cardiac hypertrophy and its impact on Badrenergic cAMP signals. Circ Res 2009;105:784-792.

[58] Patrucco E, Albergine MS, Santana LF, Beavo JA. Phosphodiesterase 8A (PDE8A) regulates excitation-contraction coupling in ventricular myocytes. J Mol Cell Cardiol 2010;49:330-3.

[59] Georget M, Mateo P, Vandecasteele G, Lipskaia L, Defer N, Hanoune J, Hoerter J, Lugnier C, Fischmeister R. Cyclic AMP compartmentation due to increased cAMPphosphodiesterase activity in transgenic mice with a cardiac-directed expression of the human adenylyl cyclase type 8 (AC8). FASEB J 2003;17:1380-1391. 
[60] Xiang Y, Naro F, Zoudilova M, Jin SL, Conti M, Kobilka B. Phosphodiesterase 4D is required for $\beta_{2}$ adrenoceptor subtype-specific signaling in cardiac myocytes. Proc Natl Acad Sci USA 2005;102:909-914.

[61] Leroy J, Abi-Gerges A, Nikolaev VO, Richter W, Lechęne P, Mazet J-L, Conti M, Fischmeister R, Vandecasteele G. Spatiotemporal dynamics of B-adrenergic cAMP signals and L-type $\mathrm{Ca}^{2+}$ channel regulation in adult rat ventricular myocytes: Role of phosphodiesterases. Circ Res 2008;102:1091-1100.

[62] Richter W, Xie M, Scheitrum C, Krall J, Movsesian MA, Conti M. Conserved expression and functions of PDE4 in rodent and human heart. Basic Res Cardiol 2011;106:249-62.

[63] Sette C, Conti M. Phosphorylation and activation of a cAMP-specific phosphodiesterase by the cAMP-dependent protein kinase - Involvement of serine 54 in the enzyme activation. J Biol Chem 1996;271:16526-16534.

[64] Oki N, Takahashi SI, Hidaka H, Conti M. Short term feedback regulation of cAMP in FRTL-5 thyroid cells. Role of PDE4D3 phosphodiesterase activation. J Biol Chem 2000;275:10831-7.

[65] Rochais F, Vandecasteele G, Lefebvre F, Lugnier C, Lum H, Mazet J-L, Cooper DMF, Fischmeister R. Negative feedback exerted by PKA and cAMP phosphodiesterase on subsarcolemmal cAMP signals in intact cardiac myocytes. An in vivo study using adenovirus-mediated expression of CNG channels. J Biol Chem 2004;279:52095-52105.

[66] Reeves ML, Leigh BK, England PJ. The identification of a new cyclic nucleotide phosphodiesterase activity in human and guinea-pig cardiac ventricle. Implications for the mechanism of action of selective phosphodiesterase inhibitors. Biochem $\mathbf{J}$ 1987;241:535-541.

[67] Shahid M, Nicholson CD. Comparison of cyclic nucleotide phosphodiesterase isoenzymes in rat and rabbit ventricular myocardium - Positive inotropic and phosphodiesterase inhibitory effects of Org-30029, milrinone and rolipram. NaunynSchmiedebergs Arch Pharmacol 1990;342:698-705.

[68] Masunaga R, Nagasaka A, Sawai Y, Hayakawa N, Nakai A, Hotta K, Kato Y, Hishida H, Takahashi H, Naka M, Shimada Y, Tanaka T, Hidaka H, Itoh M. Changes in cyclic nucleotide phosphodiesterase activity and calmodulin concentration in heart muscle of cardiomyopathic hamsters. J Mol Cell Cardiol 2004;37:767-774.

[69] Hambleton R, Krall J, Tikishvili E, Honeggar M, Ahmad F, Manganiello VC, Movsesian MA. Isoforms of cyclic nucleotide phosphodiesterase PDE3 and their contribution to cAMP-hydrolytic activity in subcellular fractions of human myocardium. J Biol Chem 2005;280:39168-39174.

[70] Vandeput F, Wolda SL, Krall J, Hambleton R, Uher L, McCaw KN, Radwanski PB, Florio V, Movsesian MA. Cyclic nucleotide phosphodiesterase PDE1C in human cardiac myocytes. J Biol Chem 2007;282:32749-57.

[71] Rapundalo ST , Solaro RJ, Kranias EG. Inotropic responses to isoproterenol and 
phosphodiesterase inhibitors in intact guinea pig hearts: comparison of cyclic AMP levels and phosphorylation of sarcoplasmic reticulum and myofibrillar proteins. Circ Res 1989;64:104-111.

[72] Weishaar RE, Kobylarz-Singer DC, Steffen RP, Kaplan HR. Subclasses of cyclic AMP-specific phosphodiesterase in left ventricular muscle and their involvement in regulating myocardial contractility. Circ Res 1987;61:539-547.

[73] Hohl CM, Li Q. Compartmentation of cAMP in adult canine ventricular myocytes Relation to single-cell free $\mathrm{Ca}^{2+}$ transients. Circ Res 1991;69:1369-1379.

[74] Jurevicius J , Fischmeister R. cAMP compartmentation is responsible for a local activation of cardiac $\mathrm{Ca}^{2+}$ channels by B-adrenergic agonists. Proc Natl Acad Sci USA 1996;93:295-299.

[75] Zaccolo M, Pozzan T. Discrete microdomains with high concentration of cAMP in stimulated rat neonatal cardiac myocytes. Science 2002;295:1711-1715.

[76] Nikolaev VO, Lohse MJ. Monitoring of cAMP synthesis and degradation in living cells. Physiology (Bethesda) 2006;21:86-92.

[77] Miller CL, Oikawa M, Cai Y, Wojtovich AP, Nagel DJ, Xu X, Xu H, Florio V, Rybalkin SD, Beavo JA, Chen YF, Li JD, Blaxall BC, Abe J, Yan C. Role of $\mathrm{Ca}^{2+} /$ calmodulin-stimulated cyclic nucleotide phosphodiesterase 1 in mediating cardiomyocyte hypertrophy. Circ Res 2009;105:956-64.

[78] Simmons MA, Hartzell HC. Role of phosphodiesterase in regulation of calcium current in isolated cardiac myocytes. Mol Pharmacol 1988;33:664-671.

[79] Mongillo M, Tocchetti CG, Terrin A, Lissandron V, Cheung YF, Dostmann WR, Pozzan T, Kass DA, Paolocci N, Houslay MD, Zaccolo M. Compartmentalized phosphodiesterase-2 activity blunts 3 -adrenergic cardiac inotropy via an NO/cGMPdependent pathway. Circ Res 2006;98:226-234.

[80] Lugnier C. Cyclic nucleotide phosphodiesterase (PDE) superfamily: a new target for the development of specific therapeutic agents. Pharmacol Ther 2006;109:366-398.

[81] Hartzell HC, Fischmeister R. Opposite effects of cyclic GMP and cyclic AMP on $\mathrm{Ca}^{2+}$ current in single heart cells. Nature 1986;323:273-275.

[82] Hartzell HC, Simmons MA. Comparison of effects of acetylcholine on calcium and potassium currents in frog atrium and ventricle. J Physiol 1987;389:411-422.

[83] Méry P-F, Pavoine C, Pecker F, Fischmeister R. Erythro-9-(2-hydroxy-3nonyl)adenine inhibits cyclic GMP-stimulated phosphodiesterase in isolated cardiac myocytes. Mol Pharmacol 1995;48:121-130.

[84] Dittrich M, Jurevicius J, Georget M, Rochais F, Fleischmann BK, Hescheler J, Fischmeister R. Local response of L-type $\mathrm{Ca}^{2+}$ current to nitric oxide in frog ventricular myocytes. J Physiol 2001;534:109-121.

[85] Rivet-Bastide M, Vandecasteele G, Hatem S, Verde I, Benardeau A, Mercadier JJ, 
Fischmeister R. cGMP-stimulated cyclic nucleotide phosphodiesterase regulates the basal calcium current in human atrial myocytes. J Clin Invest 1997;99:2710-2718.

[86] Vandecasteele G, Verde I, Rucker-Martin C, Donzeau-Gouge P, Fischmeister R. Cyclic GMP regulation of the L-type $\mathrm{Ca}^{2+}$ channel current in human atrial myocytes. $\mathrm{J}$ Physiol 2001;533:329-340.

[87] Castro LRV, Verde I, Cooper DMF, Fischmeister R. Cyclic guanosine monophosphate compartmentation in rat cardiac myocytes. Circulation 2006;113:2221-2228.

[88] Castro LRV, Schittl J, Fischmeister R. Feedback control through cGMP-dependent protein kinase contributes to differential regulation and compartmentation of cGMP in rat cardiac myocytes. Circ Res 2010;107:1232-1240.

[89] Stangherlin A, Gesellchen F, Zoccarato A, Terrin A, Fields LA, Berrera M, Surdo NC, Craig MA, Smith G, Hamilton G, Zaccolo M. cGMP Signals modulate cAMP levels in a compartment-specific manner to regulate catecholamine-dependent signaling in cardiac myocytes. Circ Res 2011;

[90] Muller B, Stoclet J-C, Lugnier C. Cytosolic and membrane-bound cyclic nucleotide phosphodiesterases from guinea pig cardiac ventricles. Eur J Pharmacol 1992;225:263-272.

[91] Kauffman RF, Crowe VG, Utterback BG, Robertson DW. LY195115: a potent, selective inhibitor of cyclic nucleotide phosphodiesterase located in the sarcoplasmic reticulum. Mol Pharmacol 1986;30:609-616.

[92] Kerfant BG, Zhao D, Lorenzen-Schmidt I, Wilson LS, Cai S, Chen SR, Maurice DH, Backx PH. PI3KY is required for PDE4, not PDE3, activity in subcellular microdomains containing the sarcoplasmic reticular calcium ATPase in cardiomyocytes. Circ Res 2007;101:400-8.

[93] Weishaar RE, Kobylarz-Singer DC, Kaplan HR. Subclasses of cyclic AMP phosphodiesterase in cardiac muscle. J Mol Cell Cardiol 1987;19:1025-1036.

[94] Bethke T, Eschenhagen T, Klimkiewicz A, Kohl C, von der Leyen H, Mehl H, Mende U, Meyer W, Neumann J, Rosswag S, Schmitz W, Scholz H, Starbatty J, Stein B, Wenzlaff H, Döring V, Kalmar P, Haverich A. Phosphodiesterase inhibition by enoximone in preparations from nonfailing and failing human hearts.

Arzneimittelforschung 1992;42:437-445.

[95] Patrucco E, Notte A, Barberis L, Selvetella G, Maffei A, Brancaccio M, Marengo S, Russo G, Azzolino O, Rybalkin SD, Silengo L, Altruda F, Wetzker R, Wymann MP, Lembo G, Hirsch E. PI3Kgamma modulates the cardiac response to chronic pressure overload by distinct kinase-dependent and -independent effects. Cell 2004;118:375387.

[96] Perino A, Ghigo A, Ferrero E, Morello F, Santulli G, Baillie GS, Damilano F, Dunlop AJ, Pawson C, Walser R, Levi R, Altruda F, Silengo L, Langeberg LK, Neubauer G, Heymans S, Lembo G, Wymann MP, Wetzker R, Houslay MD, Iaccarino G, Scott JD, Hirsch E. Integrating cardiac $\mathrm{PIP}_{3}$ and cAMP signaling through a PKA anchoring 
function of p110gamma. Mol Cell 2011;42:84-95.

[97] Marcantoni A, Levi RC, Gallo MP, Hirsch E, Alloatti G. Phosphoinositide 3kinasegamma (PI3Kgamma) controls L-type calcium current $(\mathrm{I}(\mathrm{Ca}, \mathrm{L}))$ through its positive modulation of type-3 phosphodiesterase (PDE3). J Cell Physiol 2006;206:329-336.

[98] Nikolaev VO, Bunemann M, Schmitteckert E, Lohse MJ, Engelhardt S. Cyclic AMP imaging in adult cardiac myocytes reveals far-reaching $\beta_{1}$-adrenergic but locally confined $\beta_{2}$-adrenergic receptor-mediated signaling. Circ Res 2006;99:1084-1091.

[99] Verde I, Vandecasteele G, Lezoualc'h F, Fischmeister R. Characterization of the cyclic nucleotide phosphodiesterase subtypes involved in the regulation of the L-type $\mathrm{Ca}^{2+}$ current in rat ventricular myocytes. Br J Pharmacol 1999;127:65-74.

[100] Lehnart SE, Wehrens XHT, Reiken S, Warrier S, Belevych AE, Harvey RD, Richter W, Jin SLC, Conti M, Marks A. Phosphodiesterase 4D deficiency in the ryanodine receptor complex promotes heart failure and arrhythmias. Cell 2005;123:23-35.

[101] Katano Y, Endoh M. Effects of a cardiotonic quinolinone derivative Y-20487 on the isoproterenol-induced positive inotropic action and cyclic AMP accumulation in rat ventricular myocardium: comparison with rolipram, Ro 20-1724, milrinone, and isobutylmethylxanthine. J Cardiovasc Pharmacol 1992;20:715-722.

[102] Vargas ML, Hernandez J, Kaumann AJ. Phosphodiesterase PDE3 blunts the positive inotropic and cyclic AMP enhancing effects of CGP12177 but not of noradrenaline in rat ventricle. Br J Pharmacol 2006;147:158-63.

[103] Galindo-Tovar A, Kaumann AJ. Phosphodiesterase-4 blunts inotropism and arrhythmias but not sinoatrial tachycardia of (-)-adrenaline mediated through mouse cardiac ß1-adrenoceptors. Br J Pharmacol 2008;153:710-20.

[104] Katano Y, Endoh M. Differential effects of Ro 20-1724 and isobutylmethylxanthine on the basal force of contraction and beta-adrenoceptor-mediated response in the rat ventricular myocardium. Biochem Biophys Res Commun 1990;167:123-9.

[105] Kaumann A, Semmler AB, Molenaar P. The effects of both noradrenaline and CGP12177, mediated through human $\beta_{1}$-adrenoceptors, are reduced by PDE3 in human atrium but PDE4 in CHO cells. Naunyn Schmiedebergs Arch Pharmacol 2007;375:123-31.

[106] Christ T, Engel A, Ravens U, Kaumann AJ. Cilostamide potentiates more the positive inotropic effects of (-)-adrenaline through $B_{2}$-adrenoceptors than the effects of (-)noradrenaline through $\beta_{1}$-adrenoceptors in human atrial myocardium. Naunyn Schmiedebergs Arch Pharmacol 2006;374:249-53.

[107] Bolger GB, Conti M, Houslay MD. Cellular functions of PDE4 enzymes. In: Cyclic Nucleotide Phosphodiesterases in Health and Disease, S. Francis, J.A. Beavo, M.D. Houslay (Eds), CRC Press, Taylor \& Francis Group 2007; Chapter 6:99-130.

[108] Terrin A, Di Benedetto G, Pertegato V, Cheung YF, Baillie G, Lynch MJ, Elvassore N, Prinz A, Herberg FW , Houslay MD, Zaccolo M. PGE1 stimulation of HEK293 
cells generates multiple contiguous domains with different [cAMP]: role of compartmentalized phosphodiesterases. J Cell Biol 2006;175:441-51.

[109] Leroy J, Richter W, Mika D, Castro LRV, Abi-Gerges A, Xie M , Scheitrum C, Lefebvre F, Schittl J, Westenbroek R, Catterall WA, Charpentier F, Conti M, Fischmeister R, Vandecasteele G. Phosphodiesterase 4B in the cardiac L-type $\mathrm{Ca}^{2+}$ channel complex regulates $\mathrm{Ca}^{2+}$ current and protects against ventricular arrhythmias. $\mathrm{J}$ Clin Invest 2011; (in press) PMID: 21670503.

[110] Baillie GS, Houslay MD. Arrestin times for compartmentalised cAMP signalling and phosphodiesterase-4 enzymes. Curr Op Biol 2005;17:1-6.

[111] Baillie GS, Huston E, Scotland G, Hodgkin M, Gall I, Peden AH, MacKenzie C, Houslay ES, Currie R, Pettitt TR, Walmsley AR, Wakelam MJ, Warwicker J, Houslay MD. TAPAS-1, a novel microdomain within the unique $\mathrm{N}$-terminal region of the PDE4A1 cAMP-specific phosphodiesterase that allows rapid, $\mathrm{Ca}^{2+}$-triggered membrane association with selectivity for interaction with phosphatidic acid. J Biol Chem 2002;277:28298-28309.

[112] Verde I, Pahlke G, Salanova M, Zhang G, Wang S, Coletti D, Onuffer J, Jin SLC, Conti M. Myomegalin is a novel protein of the Golgi/centrosome that interacts with a cyclic nucleotide phosphodiesterase. J Biol Chem 2001;276:11189-11198.

[113] Lugnier C, Keravis T, Le Bec A, Pauvert O, Proteau S, Rousseau E. Characterization of cyclic nucleotide phosphodiesterase isoforms associated to isolated cardiac nuclei. Biochim Biophys Acta 1999;1472:431-446.

[114] Houslay MD, Adams DR. PDE4 cAMP phosphodiesterases: modular enzymes that orchestrate signalling cross-talk, desensitization and compartmentalization. Biochem J 2003;370:1-18.

[115] Carlisle Michel JJ, Dodge KL, Wong W, Mayer NC, Langeberg LK, Scott JD. PKAphosphorylation of PDE4D3 facilitates recruitment of the mAKAP signalling complex. Biochem J 2004;381:587-592.

[116] Hoffmann R, Baillie GS, MacKenzie SJ, Yarwood SJ, Houslay MD. The MAP kinase ERK2 inhibits the cyclic AMP-specific phosphodiesterase HSPDE4D3 by phosphorylating it at Ser579. EMBO J 1999;18:893-903.

[117] Perry SJ, Baillie GS, Kohout TA, McPhee I, Magiera MM, Ang KL, Miller WE, McLean AJ, Conti M, Houslay MD, Lefkowitz RJ. Targeting of cyclic AMP degradation to $\beta_{2}$-adrenergic receptors by $\beta$-arrestins. Science 2002;298:834-6.

[118] Lynch MJ, Baillie GS, Mohamed A, Li X, Maisonneuve C, Klussmann E, van Heeke G, Houslay MD. RNA silencing identifies PDE4D5 as the functionally relevant cAMP phosphodiesterase interacting with beta -arrestin to control the PKA/AKAP79mediated switching of the $\beta_{2}$-adrenergic receptor to activation of ERK in HEK293 cells. J Biol Chem 2005;280(39):33178-33189.

[119] Baillie GS, Sood A, McPhee I, Gall I, Perry SJ, Lefkowitz RJ, Houslay MD. $\beta$ Arrestin-mediated PDE4 cAMP phosphodiesterase recruitment regulates $\beta$ adrenoceptor switching from $G_{s}$ to $G_{i}$. Proc Natl Acad Sci USA 2003;100:941-945. 
[120] Houslay MD, Baillie GS. The role of ERK2 docking and phosphorylation of PDE4 cAMP phosphodiesterase isoforms in mediating cross-talk between the cAMP and ERK signalling pathways. Biochem Soc Trans 2003;31:1186-1190.

[121] Richter W, Day P, Agraval R, Bruss MD, Granier S, Wang YL, Rasmussen SGF, Horner K, Wang P, Lei T, Patterson AJ, Kobilka BK, Conti M. Signaling from $ß_{1-}$ and $\mathrm{B}_{2}$-adrenergic receptors is defined by differential interactions with PDE4. Embo J 2008;27:384-393.

[122] De Arcangelis V, Liu R, Soto D, Xiang Y. Differential association of phosphodiesterase $4 \mathrm{D}$ isoforms with $\beta_{2}$-adrenoceptor in cardiac myocytes. J Biol Chem 2009;284:33824-32.

[123] Smith CJ, Huang R, Sun D, Ricketts S, Hoegler C, Ding JZ, Moggio RA, Hintze TH. Development of decompensated dilated cardiomyopathy is associated with decreased gene expression and activity of the milrinone-sensitive cAMP phosphodiesterase PDE3A. Circulation 1997;96:3116-3123.

[124] Sato N, Asai K, Okumura S, Takagi G, Shannon RP, FujitaYamaguchi Y, Ishikawa Y, Vatner SF, Vatner DE. Mechanisms of desensitization to a PDE inhibitor (Milrinone) in conscious dogs with heart failure. Am J Physiol Heart Circ Physiol 1999;45:H1699-H1705.

[125] Ding B, Abe J, Wei H, Xu H, Che W, Aizawa T, Liu W, Molina CA, Sadoshima J, Blaxall BC, Berk BC, Yan C. A positive feedback loop of phosphodiesterase 3 (PDE3) and inducible cAMP early repressor (ICER) leads to cardiomyocyte apoptosis. Proc Natl Acad Sci USA 2005;102:14771-14776.

[126] Ding B, Abe J, Wei H, Huang Q, Walsh RA, Molina CA, Zhao A, Sadoshima J, Blaxall BC, Berk BC, Yan C. Functional role of phosphodiesterase 3 in cardiomyocyte apoptosis: implication in heart failure. Circulation 2005;111:24692476.

[127] Nagendran J , Archer SL, Soliman D, Gurtu V, Moudgil R, Haromy A, St Aubin C, Webster L, Rebeyka IM, Ross DB, Light PE, Dyck JR, Michelakis ED.

Phosphodiesterase type 5 is highly expressed in the hypertrophied human right ventricle, and acute inhibition of phosphodiesterase type 5 improves contractility. Circulation 2007;116:238-48.

[128] Mokni W, Keravis T, Etienne-Selloum N, Walter A, Kane MO, Schini-Kerth VB, Lugnier C. Concerted regulation of cGMP and cAMP phosphodiesterases in early cardiac hypertrophy induced by angiotensin II. PLoS One 2010;5:e14227.

[129] Yan C, Miller CL, Abe J. Regulation of phosphodiesterase 3 and inducible cAMP early repressor in the heart. Circ Res 2007;100:489-501.

[130] Schroder F, Handrock R, Beuckelmann DJ, Hirt S, Hullin R, Priebe L, Schwinger RHG, Weil J, Herzig S. Increased availability and open probability of single L-type calcium channels from failing compared with nonfailing human ventricle. Circulation 1998;98:969-976.

[131] Chen X, Piacentino VI, Furukawa S, Goldman B, Margulies KB, Houser SR. L-type 
$\mathrm{Ca}^{2+}$ channel density and regulation are altered in failing human ventricular myocytes and recover after support with mechanical assist devices. Circ Res 2002;91:517-24.

[132] Dodge-Kafka KL, Langeberg L, Scott JD. Compartmentation of cyclic nucleotide signaling in the heart: the role of A-kinase anchoring proteins. Circ Res 2006;98:9931001 .

[133] Willoughby D, Cooper DM. Organization and $\mathrm{Ca}^{2+}$ regulation of adenylyl cyclases in cAMP microdomains. Physiol Rev 2007;87:965-1010.

[134] Stork PJS, Schmitt JM. Crosstalk between cAMP and MAP kinase signaling in the regulation of cell proliferation. Trends Cell Biol 2002;12:258-266.

[135] Osadchii OE. Cardiac hypertrophy induced by sustained $\beta$-adrenoreceptor activation: pathophysiological aspects. Heart Fail Rev 2007;12:66-86.

[136] Movsesian MA. Altered cAMP-mediated signalling and its role in the pathogenesis of dilated cardiomyopathy. Cardiovasc Res 2004;62:450-459.

[137] Movsesian MA, Bristow MR. Alterations in cAMP-mediated signaling and their role in the pathophysiology of dilated cardiomyopathy. Curr Top Dev Biol 2005;68:25-48. 